\title{
Confirmed Neuromeningeal Tuberculosis in Patients Living with HIV
}

\author{
Badi Hanane*, El Fane Mouna, Oulad Lahsen Ahd, Sodqi Mustapha, Marih Latifa, Bensghir Rajaa, Chakib \\ Abdelfettah and Marhoum El Filali Kamal
}

Department of infectious diseases, Ibn Rochd University Hospital, Morocco

Submission: January 25, 2019; Published: March 12, 2019

*Corresponding author: Badi Hanane, Department of infectious diseases, Ibn Rochd University Hospital, Morocco

\begin{abstract}
Introduction: Neuromeningeal tuberculosis remains a public health issue in low- and middle-income countries. The huge clinical and radiologic polymorphism is frequently responsible of a delay in diagnosis and then in patient's care. The aim of this study is to describe the clinical, paraclinical and the evolutive course of neuromeningeal tuberculosis in patients living with HIV.

Patients and methods: It's a retrospective study including patients living with HIV who had a confirmed neuromeningeal tuberculosis and been cared for in the infectious diseases department of Ibn Rochd University Hospital of Casablanca between January 2012 and December 2017. The data were collected from computerized medical files on Nadis software.

Results: We gathered thirty-two patient's files, among whom seventeen females with a mean age of $36 \pm 39$ years old. The median of CD4 levels was 186 cells $/ \mathrm{mm} 3$. The mean time line between the beginning of the symptoms and the seek of care was thirty-three days (6-90 days). The neuromeningeal tuberculosis revealed HIV in 20 cases (62.5\%). The main clinical presentations were the meningitis syndrome in 22 cases and unconsciousness in 7 cases. The head scan realized on all patients was abnormal in $69 \%$ of the cases showing tuberculoma in six cases, hydrocephalus in seven cases and a hypodensities in nine cases. The cerebro-Spinal Fluid (CSF) was clear in 29 cases with lymphocytosis, high levels of proteins and low glycorrachia levels in respectively $75 \%, 90 \%$, and $75 \%$ of the cases. Ziehl-Neelsen staining was negative in all cases and Lowenstein culture positive in $78 \%$ of the cases. The TB-PCR on CSF was positive on all fifteen cases that benefited from it. Eighteen patients had other localizations, fifteen of which are pulmonary tuberculosis and ten others are lymph node tuberculosis. The mortality rate was $53 \%$.

Conclusion: Neuromeningeal tuberculosis has an extremely heterogeneous clinical and radiologic presentation among HIV infected patients. The prognosis depends on the immune status of the patient and the time line between the diagnosis and the instauration of treatment.
\end{abstract}

Keywords: Confirmed neuromeningeal tuberculosis; Cerebrospinal fluid; Tuberculoma; HIV infection

Abbrevations: ART: Antiretroviral Therapy, CSF: Cerebrospinal Fluid's, IRIS: Inflammatory Syndrome, UHC: University Hospital Center, ZN: Ziehl-Neelsen, PCR: Polymerase Chain Reaction, AFB: Acid-Fast Bacilli, NAA: Nucleic and Amplification

\section{Introduction}

Tuberculosis (TB) remains a major public health problem in Morocco and represents the most frequent AIDS-defining opportunistic infection [1]. The annual incidence of TB in Morocco was estimated at 83/100 000 people per year in adult population and the prevalence of HIV infection among TB patients is $1.7 \%$ [2]. HIV intensely increases the risk of Tuberculous Meningitis (TBM) because there is a higher susceptibility to reactivating and disseminating $\mathrm{TB}$ in these patients $[3,4]$. TBM is one of the most severe and lethal complications of TB [5]. TBM is caused by the hematogenous spread of the pulmonary bacilli or from the rupture of sub-ependymal tubercule into the subarachnoid space $[6,7]$. However, the mechanism by which the bacilli invade the blood-brain barrier and the exact trigger of discharge into the subarachnoid space is not fully understood yet [6]. TBM diagnosis and treatment are complicated due to the variable Cerebrospinal Fluid's formula presentation (CSF), the drug interactions and the decision making of the proper timing of Antiretroviral Therapy (ART) initiation after starting the patient on TBM treatment with an awareness of the possibility of an occurrence of an immune reconstitution Inflammatory Syndrome (IRIS) [3]. IRIS develops in 9 to $47 \%$ HIV patients who are diagnosed with TBM and who started ART; it is associated 


\section{Open Access Journal of Neurology \& Neurosurgery}

with a mortality rate of 13 to $75 \%$ [8]. TBM in patients living with HIV have an increased risk of poor clinical outcomes with mortality rates as high as $67 \%$ against $25 \%$ of HIV negative patients [7]. In Morocco, the studies are scarce even with the gravity of HIV and TB infections situation. Furthermore, although all patients have a free access to ARV and TB medications, the majority of HIV-infected patients with TBM still present with severe immunosuppression. This study was designed to outline the characteristics of TBM in HIV infected patients in Morocco.

\section{Materials and Methods}

This was a retrospective study of TBM in HIV infected patients at the University Hospital Center (UHC) of Casablanca, conducted between January 2012 and December 2017. The diagnosis was based on combining the clinical symptoms, CSF analysis and radiological features and confirmed by culture or TB-PCR on CSF. All patients benefited from a macroscopic examination, a protein and glucose quantification, a cell count, a Ziehl-Neelsen (ZN) staining and Mycobacterium tuberculosis culture on Lowenstein-Jensen medium on CSF. Some patients had also TB Polymerase Chain Reaction (PCR) tests (real time PCR, 2720 thermal technology, applied biosystem by life technology, USA). Brain CT was performed in all cases to exclude mass effect prior to lumbar puncture and brain MRI when indicated to highlight tuberculoma. Tuberculomas were identified as a low or high-density rounds or lobulated masses with irregular borders showing ring enhancement after contrast injection. Chest X-ray and sputum samples were collected to look for pulmonary TB. Further analysis were indicated according to symptoms. CSF finding consistent with TBM include high protein, low glucose and a high mononuclear to polynuclear leucocyte ratio. Identification of M. tuberculosis thanks to culture and molecular analysis. Patients were treated with standardized TB treatment; including isoniazid, rifampicin, pyrazinamide, and ethambutol for two months, followed by rifampicin and isoniazid for at least seven months. Total duration varied from nine to twelve months. ART was advised for all patients. The first line of treatment was tenofovir, emtricitabine, efavirenz or nevirapine. Data were collected from computerized medical files on Nadis software and analyzed using Excel support.

\section{Results}

During the study period, 32 cases of confirmed tuberculosis meningitis in patients living with HIV were observed. The prevalence of confirmed tuberculous meningitis among HIV patients was $1.14 \%$, 94\% were Moroccan and two patients were from Mali. A slight majority of patients were female $(n=17,53 \%)$ and the mean age was $36 \pm 39$ years. Patient demographic data are shown in Table 1. Most patients (90\%) had heterosexual intercourses risk factor. Majority of patients were from low socio-economic backgrounds (80\%). Eleven (34\%) cases have a history of previous TB and 7 (22\%) patients came in contact with tubercular patients. The symptoms progressed for four weeks or more before admission. Majority of patients have a general signs of TB infection (night sweat seen in $80 \%$, weight loss in 76\%). Pulmonary symptoms were rarely the presenting symptoms (30\%) of cases. The most common clinical manifestations were headache $(87.5 \%)$ and fever (47\%). Typical meningeal syndrome was observed in $22(69 \%)$ patients. Neurological symptoms noted on admission were unconsciousness $(21.8 \%)$, motor deficiency (15.6\%) and convulsions (31.2\%). The clinical presentations are summarized in Table 1.

Table 1: Demographic, clinical and CSF characteristics of patients with tuberculous meningitis (TBM).

\begin{tabular}{|c|c|c|}
\hline \multicolumn{3}{|c|}{ Demographic Data } \\
\hline Age, median (IQR) & 36 & $21-58$ \\
\hline Female, N (\%) & 17 & 53 \\
\hline Previous TB, n/N (\%) & 11 & 34 \\
\hline Signs and Symptoms at Presentation, N/N (\%) \\
\hline Weight loss & 24 & 76 \\
\hline Fever & 15 & 47 \\
\hline Headache & 28 & 87.5 \\
\hline Unconsciousness & 7 & 22 \\
\hline Meningitis syndrome & 22 & 69 \\
\hline Convulsions & 10 & 31.2 \\
\hline Motor deficiency & 5 & 15.6 \\
\hline Cerebrospinal Fluid Results, Median, (IQR) \\
\hline Protein (mg/dL) & 0,83 & $0,2-3,09$ \\
\hline Glucose (mg/dL) & 0,4 & $0,18-1,38$ \\
\hline White cell (cells*106 /L) & 108 & $0-700$ \\
\hline
\end{tabular}

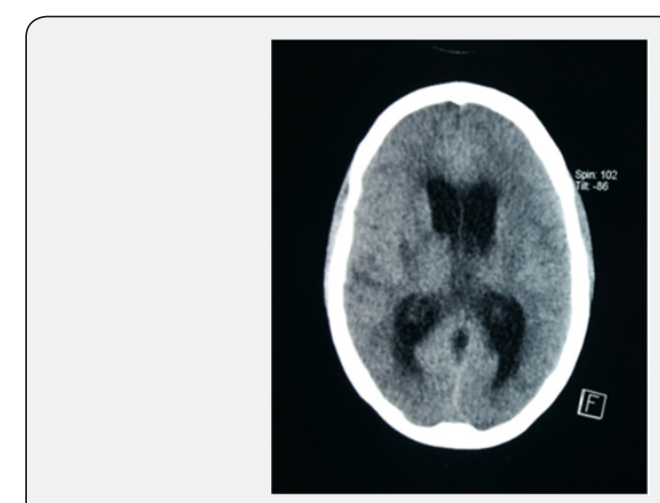

Figure 1:CT scan: ventricular dilation representing hydrocephalus.

All patients underwent brain CT though 19\% of them had brain MRI with gadolinium, the majority of which $(n=22,68.7 \%)$ was abnormal: a hypodensity was seen in 9 (28\%) cases, 7 $(22 \%)$ demonstrated hydrocephalus and tuberculoma was found in $6(18.7 \%)$ cases. (Figures 1\&2). CSF examinations are summarized in Table $175 \%$ of cases showed a lymphocytic pleocytosis. The median protein level was $0,83 \mathrm{mg} / \mathrm{dL}$ (IQR: 0.2 3.09), median glucose level was $0,4 \mathrm{mg} / \mathrm{dL}$ (IQR: 0.18-1.38) and median white cell count (WCC) was 108 cells/ml (IQR: 0-700). A 
protein level was more than $0.4 \mathrm{mg} / \mathrm{dL}$ in 29 (90\%), a glucose concentration was less or equal to $0.45 \mathrm{mg} / \mathrm{dL}$ in 24 (75\%) cases. No Acid-Fast Bacilli (AFB) smears were positive. Mycobacterium tuberculosis was cultured from 25/32 CSF samples (78 \%). PCR was positive in fifteen cases (n: 15/32, 47\%); No TB was of a multidrug resistant. Eighteen (56\%) patients had extrameningeal TB. Chest radiography was consistent with TB in 15 (83\%) cases, the most frequent pulmonary lesions identified were infiltrates $(57 \%)$ and cavities (26\%). Four (22\%) patients presented with miliary TB. Ten (55.5\%) patients had lymph node tuberculosis; four had hematopoietic tuberculosis and two scrotal localization. The median CD4 count was 186 cells/ $\mu \mathrm{L}$ (IQR = 39-237). The majority of patients (78\%) had CD4 count less than 200 cell $/ \mathrm{mm} 3$. HIV diagnosis was concomitant to TB diagnosis in $62.5 \%$ of cases. Only four patients $(12.5 \%)$ were receiving ART at the time of hospital admission. TB treatment was initiated immediately after clinical suspicion for a period of 9 to 12 months. Adjunction of steroid therapy was initiated in $69 \%$ cases at a dose of $1.5 \mathrm{mg} / \mathrm{kg} /$ day during the first month and gradually reduced during the second month. Nine $(28 \%)$ patients developed reversible side effects: five with Isoniazid and four with Rifampicin. Four patients (12.5\%) needed a ventriculo-peritoneal shunt for hydrocephalus. Three $(9.3 \%)$ patients developed IRIS with a median of time onset of three to six months. Thirteen (41\%) patients well recovered after TB treatment on 12 months follow up. Two patients (6\%) had a residual disability. Inpatient mortality was 53\% in average of ten days after admission. Details are shown on Table 2.

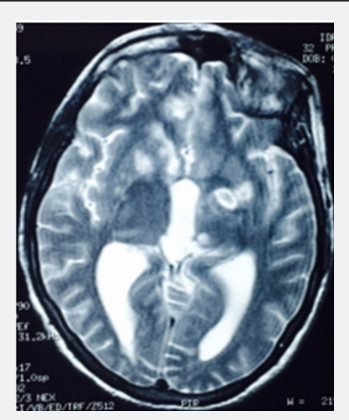

Figure 2a:Nodular periventricular hyper-intensities after injection of gadolinium representing tuberculomas.

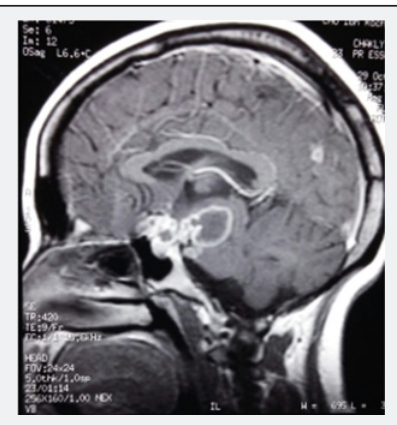

Figure 2b:cerebral MRI: sagittal T1: multiple round lesions annularly after gadolinium injection.
Table 2: Variables associated with inpatient mortality.

\begin{tabular}{|c|c|c|}
\hline \multicolumn{3}{|c|}{ Death n (\%) } \\
\hline \multirow{2}{*}{ Gender } & Male & $10(58.8)$ \\
\hline & Female & $7(41.2)$ \\
\hline \multirow{2}{*}{ Age } & $<40$ & $11(64,7)$ \\
\hline & $\geq 40$ & $6(35.3)$ \\
\hline \multirow{2}{*}{ History of previous TB } & Yes & $7(41.2)$ \\
\hline & NO & $10(58.8)$ \\
\hline \multirow{2}{*}{ ART } & Yes & $2(11.7)$ \\
\hline & No & $15(88.3)$ \\
\hline \multirow{2}{*}{ CD4 count $<200$ cells $/ \mathrm{ml}$} & Yes & $13(76.4)$ \\
\hline & No & $4(23.6)$ \\
\hline \multirow{2}{*}{ Corticotherapy } & Yes & $9(53)$ \\
\hline & No & $8(47)$ \\
\hline \multirow{2}{*}{ Disseminated TB } & Yes & $11(64.7)$ \\
\hline & No & $6(35,3)$ \\
\hline \multirow{2}{*}{ Glycorrhachia $<45 \mathrm{mg} / \mathrm{dl}$} & Yes & $12(70.5)$ \\
\hline & NO & $5(29.5)$ \\
\hline \multirow{2}{*}{ Neurological deterioration } & Yes & $15(88.2)$ \\
\hline & No & $2(11.8)$ \\
\hline \multirow{2}{*}{ IRIS } & Yes & $2(11.8)$ \\
\hline & No & $15(88.2)$ \\
\hline
\end{tabular}

\section{Discussion}

The increased incidence of HIV infection has led to the resurgence of TB in Morocco. Neurological TB occurs in 5 to 8 $\%$ in HIV infected patients; five times more frequent than in HIV negative patients $[6,9]$. TBM accounts for approximately $1 \%$ of all cases of TB [5]. This study founded that the prevalence of confirmed TBM in HIV infected patient at the UHC of Casablanca was $1,14 \%$. This result was lower than that in studies conducted in Cameroon (8\%) and India (7\%) [3]. TBM occurs most often in persons over 45 years, frequently appearing as a reactivation of a latent infection [10]. In our study, the most affected age group was between $21-45$ years in $81 \%$ of the cases. This could be explained by the young age of our population and the high incidence of TB in our country. A slight female dominance was observed, this could be explained by the feminization of HIV in Morocco. The prevalence of CNS-TB infections in females have been described in other studies from developed countries and suggest a gender related difference in the pathogenesis of TB [11].

The typical clinical presentation of meningitis is rarely found, the clinical spectrum is wide, and the onset of symptoms may be insidious or abrupt [7]. Usually, HIV infection does not modify the presentation of TBM [12], however, during HIV infection, the diagnosis of TBM is tricky due to the various diagnostic possibilities of opportunistic intracranial infections 


\section{Open Access Journal of Neurology \& Neurosurgery}

and malignancies [3]. Typical meningeal stiffness was observed in $69 \%$ of our patients and the most frequent clinical symptoms were headache $(87 \%)$ and fever (46\%), similar to those in other studies $[6,7,13-15]$. This difference could be explained by lower CD4 count of our patients and patients more severely immune depresses will present unusually [16].

However, our study was distinguished by the frequency of unconsciousness noted in $22 \%$ of cases. More so, TBM have an insidious onset with variable duration of symptoms from a few days to several months [7]. The gradual onset of symptoms before hospitalization noted in $84 \%$ of cases in our study is the same in Luma and al study [7]. Atypical CSF result are more common in HIV patients, including lower CSF protein, higher glucose levels, lower CSF WCC and even completely normal CSF finding have been reported in $25 \%$ to $33 \%$ of HIV patients with TBM [16-22]. The absence of CSF pleocytosis occur generally in patients with lymphopenia (CD4 $\mathrm{T}$ cell counts $<50$ cells/ MI), which may explain the low lymphocytes count in the CSF $[7,21]$. We found that the median WCC was much higher than in other studies [7,23]. The identification of Mycobacterium tuberculosis in CSF is the gold standard for diagnosis and for drug-susceptibility testing. Though, CSF MT culture is slow and insufficiently sensitive (roughly $60-70 \%$ ) $[3,6,24,25]$. This fact is matched in our study where confirmed diagnosis by culture was obtained in $78 \%$ of patients. Thus, CSF microscopy analysis with Ziehl-Neelson staining for AFB (acid fast bacilli) is the test used most often worldwide for TB diagnosis but has poor sensitivity (10-20\%) in TBM and cannot be relied upon to rule out TBM $[3,13,26,27]$. However, the sensitivity can be improved by increasing the CSF sample volume to $6 \mathrm{ml}$ and shortening the time for examination of the slide [6,7]. In this study, in all cases, the CSF microscopy analysis was negative. Other study had same results [7]. Nucleic and Amplification (NAA) tests on CSF have better sensitivity and specificity compared to microscopy and culture and it can speed up the diagnosis of tuberculosis from several weeks to 2 days [3,9]. In our study, PCR improved the diagnostic performance by confirming the diagnosis in fifteen smears.

For radiographic assessment of TBM, MRI is superior in detecting typical findings of TBM. However, in our unit, CT scan is a common practice in CNS disease investigation. The typical finding of TBM including brainstem involvement, leptomeningeal enhancement, vascular and cranial nerve involvement [28-30]. However, these radiographic finding are not specific to TBM and may not be sufficient to exclude other CNS co-infections [3]. An increased rate of tuberculoma in patients co-infected HIV-TB versus HIV negative patients is reported $[3,13]$. In our study, tuberculoma was seen in $18.7 \%$ of the cases, this finding is similar to that seen in one study from India (21\%) [31], and lower than what was reported in other study (45\%) [6]. Infarctions and communicating hydrocephalus are also reported in TBM [32].
They were present in only $10 \%$ of the cases [13]. They were seen on CT scans in $12 \%$ and $28 \%$ respectively of adults with TBM in other study [33,34]. The presence of extra-meningeal TB should be searched for any case of TBM using microscopy and mycobacterial culture of appropriate extra-meningeal specimens including sputum [3]. Chest $x$-ray finding were abnormal in $47 \%$ of our cases and four patients becoming culture positive. This shows the importance of not trusting chest-x ray and sputum to support the diagnosis of TBM $[9,13]$. HIV infection is recognized as the most common risk factor associated with TBM and TBM may be the initial presentation of HIV infection, as was perceived in $62.5 \%$ of our patients [35,36]. Consequently, HIV status should be defined if TBM is diagnosed [9]. Furthermore, sever immune suppression increases the odds of having TBM $[36,37]$. Leeds and al were reported that HIV infected patients with extrapulmonary TB and CD4 less than 100 were more likely to have TBM [4]. Other studies had also found that declining CD4 lymphocytes count can be associated with increasingly severe form of TB including TBM, but this remained understudied [36,38]. This is consistent with the results we got when most of patients had severe immune suppression. Previous studies reported also results of severe immune suppression with median CD4 count reaching sixteen to fourteen $[7,23,39]$. This finding contrasts a previous study conducted by Kingkaew and al, which found that $71,8 \%$ of HIV infected patients with TBM had CD4 lymphocyte counts $<100$ [40].

TB treatment should be started on once TBM is suspected because of the high case fatality [3,7]. In Morocco, the TBM treatment regimens are standardized and comply with international recommendations including those of the WHO and international Union against Tuberculosis and Lung Disease [41]. All the French and American scientific societies recommend the use of steroids in addition to TB treatment, although the results of literature are not all consistent [42-44]. In a study of 270 patients, the use of corticosteroids does not find a significant improvement in survival adult patients with TBM [45]. Another study including 545 patients showed that the adjunction of dexamethasone to the anti-TB regimen reduced mortality but did not prevent disability in survivors [46]. TBM is the most lethal form of TB especially in HIV infected patients severely immune depressed [47]. Its mortality rates are considerably increased due to HIV infection, with 9 months survival rates less than $40 \%$ in HIV infected patients, compared with more than $70 \%$ in HIV negative patients [3]. 53\% of our patients died, this case fatality is lower than that found in another study (79\%) [23]. Higher mortality rates have been described in another study conducted in Cameroon. Studies from Brazil and China reported mortality rates of $29 \%$ [40].

In HIV infected patients, a lower CD4 cell counts $[3,23]$, asymmetric neurological exam and altered consciousness on admission, were found to be a factor associated with a poor prognosis [47]. Previous study found also an association 
between immune suppression, neurological deterioration at admission and poor prognosis in HIV infected TBM patients $[6,48,49]$. Some studies reported other factors associated with death including disease progression of more than 14 days, drug resistance TB and low serum sodium concentration [23,49]. EL Sahly and al found that older patients were more likely to die within 180 days of diagnosis than younger patients [50]. TBIRIS is a severe complication, in HIV infected patients receiving TB treatment. It occurs usually approximately 2 weeks after the introduction of ART (30\%) [6]. TB-IRIS is characterized by high CSF neutrophil count and Mycobacterium tuberculosis culture positivity [49].

Cases of expanding tuberculomas and abscesses have been described in paradoxical TBM-IRIS [3]. There is no mutual agreement on treatment in terms of using steroids and the prolongation of its duration [3]. IRIS has been reported in twenty to forty percent of patients receiving TB therapy for TBM in other studies conducted in South Africa [49,51]. There were limitations to our study. Its retrospective nature, the small sample size and the study concerned only patients with confirmed TBM in one referral hospital which does not capture the global picture of the problematic of TBM among HIV-infected patients in Morocco. However, the study conclude to information that can help clinicians in diagnosis and management of TBM in HIV patients especially in a setting with limited resources.

\section{Conclusion}

What to conclude from our study is that TBM may be the initial presentation of HIV infection. Clinical presentation and lab exams are often atypical. Physicians should do a LP in the presence of any warning sign of meningitis. We have also found that TBM has a high rate of mortality in PLWH and advanced HIV stage and the presence of neurological symptoms at admission are correlated with high rate of mortality. Starting early TB treatment may decrease the mortality rate associated to ARV medications to increase CD4 count.

\section{References}

1. (2013) Direction de lépidémiologie et de lute contre les maladies Ministry of Health of Morocco. HIV prevalence: epidemiological situation of HIV infection in Morocco.

2. (2013-2016) National plan for the reduction of the impact of tuberculosis.

3. Chamie G, Marquez C, Luetkemeyer A (2014) HIV-Associated Central Nervous System Tuberculosis. SeminNeurol 34(1): 103-115.

4. Leeds I, Matthew J Magee, Ekaterina V Kurbatova, Carlos R, Henry M, et al. (2012) Site of Extrapulmonary Tuberculosis is Associated with HIV Infection. Clin Infect Dis 55(1): 75-81.

5. Giancola ML, Baldini F, Carapella CM, Rizzi EB, Maddaluno R, et al. (2015) Brain tuberculosis-associated immune reconstitution inflammatory syndrome in an HIV-positive patient: a biopsy-proven case. J Infect Dev Ctries 9(5): 536-540.

6. Daniele B (2014) Characteristics of Central Nervous System Tuberculosis in a Low-Incidence Country: a Series of 20 Cases and a Review of the Literature. Jpn J Infect Dis 67: 50-53.
7. Luma HN, Nguenkam Tchaleu BC, Mbatchou Ngahane BH, Emfack E, Doualla MS, et al. (2013) Tuberculous meningitis: presentation, diagnosis and outcome in HIV-infected patients at the douala general hospital, cameroon: a cross sectional study. AIDS Res Ther 10: 16.

8. Bahr N, Boulware DR, Scriven J, Wilkinson RJ, Meintjes G (2013) Central Nervous System Immune Reconstitution Inflammatory Syndrome Curr Infect Dis Rep 15(6): 583-93.

9. Michelle Whiteman, Luis Espinoza, Judith Donovan Post M, Michael D Bell, Steve Falcone (1995) Central Nervous System Tuberculosis in HIV-Infected Patients: Clinical and Radiographic Findings. AJNR Am J Neuroradiol 16:1319-1327.

10. Truffot-Pernot C, De Benoist AC, Swoebel D, Trystram D, Grosset J, et al. (1998) Active surveillance of tuberculous meningitis in France in 1995. Weekly Epidemiological Bulletin 12: 49-50.

11. Forssbohm M, Zwalhen M, Loddenkemper R, Rieder HL (2008) Demographic characteristics of patients with extrapulmonary tuberculosis in Germany. Eur Respir J 31(1): 99-105.

12. Thwaites GE, Duc Bang N, Huy Dung N, Thi Quy H, Thi Tuong Oanh D, et al. (2005) The influence of HIV infection on clinical presentation, response to treatment, and outcome in adults with Tuberculous meningitis. J Infect Dis 192(12): 2134-2141.

13. Pascallina LC Ting, Norton R (2013) Central nervous system tuberculosis: A disease from Papua New Guinea in North Queensland. J Paediatr Child Health 49(3): 193-198.

14. Cohen DB, Zijlstra EE, Mukaka M, Reiss M, Kamphambale S, et al. (2010) Diagnosis of cryptococcal and tuberculous meningitis in a resource-limited African setting. Trop Med Int Health 15 (8): 910-917.

15. Hosoglu S, Geyik MF, Balik I, Aygen B, Erol S, et al. (2003) Tuberculous meningitis in adults in Turkey: epidemiology, diagnosis, clinic and laboratory. Eur J Epidemiol 18 (4): 337-343.

16. Pasco PM (2012) Diagnostic features of tuberculous meningitis: a cross-sectional study. BMC Res Notes 5: 49.

17. Donald PR, Schaaf HS, Schoeman JF (2005) Tuberculous meningitis and miliary tuberculosis: the Rich focus revisited. J Infect 50 (3): 193195.

18. Cecchini D, Ambrosioni J, Brezzo C, Corti M, Rybko A et al. (2009) Tuberculous meningitis in HIV-infected and non-infected patients: comparison of cerebrospinal fluid findings. Int J Tuberc Lung Dis 13(2): 269-271.

19. Katrak SM, Shembalkar PK, Bijwe SR, Bhandarkar LD (2000) The clinical, radiological and pathological profile of tuberculous meningitis in patients with and without human immunodeficiency virus infection. J Neurol Sci 181(1-2): 118-126.

20. Phypers M, Harris T, Power C (2006) CNS tuberculosis: a longitudinal analysis of epidemiological and clinical features. Int J Tuberc Lung Dis 10(1): 99-103.

21.Vidal JE, de Oliveira AC, Hernández AV (2010) CD4p T-cell count and cerebrospinal fluid findings in HIV-infected patients with tuberculous meningitis. Int J Tuberc Lung Dis 14(11): 1496-1497.

22. Rana FS, Hawken MP, Mwachari C, Bhatt SM, Abdullah F, et al. (2000) Autopsy study of HIV-1-Cpositive and HIV-1-negative adult medical patients in Nairobi, Kenya. J Acquir Immune Defic Syndr 24(1): 23-29.

23. Marais S, Pepper DJ, Schutz C, Wilkinson RJ, Meintjes G (2011) Presentation and Outcome of Tuberculous Meningitis in a High HIV Prevalence Setting. PLoS One 6(5): 1-10.

24. Garg RK, Sinha MK (2011) Tuberculous meningitis in patients infected with human immunodeficiency virus. J Neurol 258(1): 3-13. 


\section{Open Access Journal of Neurology \& Neurosurgery}

25. Pasco PM (2012) Diagnostic features of tuberculous meningitis: a cross-sectional study. BMC research notes 5: 49.

26. Man H, Sellier P, Boukobza M, Clevenbergh P, Diemer M, et al. (2010) Central nervous system tuberculomas in 23 patients. Scand J Infect Dis 42(6-7): 450-454.

27. Tinsa F, Essaddam L, Fitouri Z, Boussetta K, Ben Becher S, et al. (2010) Central system nervous tuberculosis in infants. J Child Neurol 25(1): 102-106.

28. Thwaites GE (2013) Advances in the diagnosis and treatment of tuberculous meningitis. Curr Opin Neurol 26(3): 295-300.

29. Van der Merwe DJ, Andronikou S, Van Toorn R, Pienaar M (2009) Brainstem ischemic lesions on MRI in children with tuberculous meningitis: with diffusion. weighted confirmation. Childs Nerv Syst 25(8): 949-954

30. Bernaerts A, Vanhoenacker FM, Parizel PM, Van Goethem JW, Van Altena R, et al. (2003) Tuberculosis of the central nervous system overview of neuroradiological findings. Eur Radiol 13(8): 1876-1890.

31. Anuradha HK, Garg RK, Sinha MK, Agarwal A, Verma R, et al. (2011) Intracraniatuberculomas in patients with tuberculous meningitis: predictors and prognostic significance. Int J Tuberc Lung Dis 152(2): 234-239.

32. Thwaites GE, Duc Bang N, Huy Dung N, Thi Quy H, Thi Tuong Oanh D, et al. (2005) The influence of HIV infection on clinical presentation, response to treatment, and outcome in adults with tuberculous meningitis. J Infect Dis 192(12): 2134-2141.

33. Tartaglione T, Di Lella GM, Cerase A, Leone A, Moschini M, et al. (1998) Diagnostic imaging of neurotuberculosis. Rays 23(1): 164-180.

34. Li J, Afroz S, French E, Mehta A (2016) Patient Presenting with Tuberculous Encephalopathy and Human Immunodeficiency Virus Infection. Am J Case Rep 17: 406-411.

35. Sterling TR, Dorman SE, Chaisson RE, Ding L, Hackman J, et al (2001) Human immunodeficiency virus-seronegative adults with extrapulmonary tuberculosis have abnormal innate immune responses. Clin Infect Dis 33(7): 976-982.

36. Jones BE, Young SM, Antoniskis D, Davidson PT, Kramer F, et al. (1993) Relationship of the manifestations of tuberculosis to CD4 cell counts in patients with human immunodeficiency virus infection. Am Rev Respir Dis 148(5): 1292-1297.

37. Kingkaew N, Sangtong B, Amnuaiphon W, Jongpaibulpatana J, Mankatittham W, et al. (2009) HIV-associated extrapulmonary tuberculosis in Thailand: epidemiology and risk factors for death. Int J Infect Dis 13(6): 722-729.

38. De Cock KM, Soro B, Coulibaly IM, Lucas SB (1992) Tuberculosis and HIV infection in sub-Saharan Africa. JAMA 268(12): 1581-1587.
39. Dai L, Mahajan SD, Guo C, Zhang T, Wang W (2014) Spectrum of central nervous system disorders in hospitalized HIV/AIDS patients (20092011) at a major HIV/AIDS referral center in Beijing, China. J Neurol Sci 342(1-2): 88-92.

40. Jaryal A, Raina R, Sarkar M, Sharma A (2011) Manifestations of tuberculosis in HIV/AIDS patients and its relationship with CD4 count. Lung India 28(4): 263-266.

41. (2010) WHO Treatment of Tuberculosis Guidelines $4^{\text {th }}$ (Ed), Geneva, Switzerland.

42. (2004) Recommandation de la Société de pneumologie de Langue Française sur la prise en charge de la tuberculose en France. Conférence d'experts - texte court 21(3): 5-11.

43. (2003) Prévention et prise en charge de la tuberculose en France. Synthèse et recommandation du groupe de travail du conseil d'hygiène Publique de France. Rev Mal Respir 20:7S7-106.

44. Blumberg HM, Burman WJ, Chaisson RE, Daley CL, Etkind SC, et al (2003) American Thoracic Society / Center for Disease Control and Prevention / Infectious Disease Soxiety of America. Treatment of tuberculosis. Am J Respir Crit Care Med 167(4): 603-662.

45. Madani N, Dendane T, Zekraoui A, Abidi K, Zeggwagh AA, et al. (2009) Effets de la corticothérapie chez les adultes admis en réanimation pour méningite tuberculeuse: analyse par le score de propension. Rev Med Int 30(1): 12-19.

46. Thwaites GE, Nguyen DB, Nguyen HD, Hoang TQ Do TT, et al. (2004) Adjunctive treatment with dexamethasone reduced the risk of death in Vietnam. N Engl J Med 351(17): 1741-1751.

47. Gordon SB, Walsh AL, Chaponda M, Gordon MA, Soko D, et al. (2000) Bacterial meningitis in Malawian adults: pneumococcal disease is common, severe, and seasonal. Clin Infect Dis 31(1): 53-57.

48. Cecchini D, Ambrosioni J, Brezzo C, Corti M, Rybko A, et al. (2007) Tuberculous meningitis in HIV-infected patients: drug susceptibility and clinical outcome. AIDS 21(3): 373-374.

49. Marais S, Meintjes G, Pepper DJ, Dodd LO, Schutz C, et al. (2013) Frequency, Severity, and Prediction of Tuberculous Meningitis Immune Reconstitution Inflammatory Syndrome. Clin Infect Dis 56(3): 450460 .

50. El Sahly HM, Teeter LD, Pan X, Musser JM, Graviss EA (2007) Mortality associated with central nervous system tuberculosis. J Infect 55(6): 502-509.

51. Hosoglu S, Geyik MF, Balik I, Aygen B, Erol S, et al. (2002) Predictors of outcome in patients with tuberculous meningitis. Int J Tuberc Lung Dis 6(1): 64-70. 
(C) This work is licensed under Creative BY DOI: 10.19080/OAJNN.2019.09.555775

\section{Your next submission with Juniper Publishers will reach you the below assets}

- Quality Editorial service

- Swift Peer Review

- Reprints availability

- E-prints Service

- Manuscript Podcast for convenient understanding

- Global attainment for your research

- Manuscript accessibility in different formats ( Pdf, E-pub, Full Text, Audio)

- Unceasing customer service

Track the below URL for one-step submission https://juniperpublishers.com/online-submission.php 